\title{
Antibiotic resistance: what are the opportunities for primary care in alleviating the crisis?
}

\section{Malene Plejdrup Hansen ${ }^{1}$, Tammy C. Hoffmann ${ }^{1}$, Amanda R. McCullough ${ }^{1}$, Mieke L. van Driel ${ }^{2}$ and Chris B. Del Mar ${ }^{1}$ *}

1 Centre for Research in Evidence-Based Practice, Bond University, Gold Coast, QLD, Australia

${ }^{2}$ Discipline of General Practice, School of Medicine, University of Queensland, Brisbane, QLD, Australia

\section{Edited by:}

Aline Ramond-Roquin, University of

Angers, France

\section{Reviewed by:}

Julie Dupouy, Université Paul

Sabatier, France

Olivier Saint-Lary, Université de

Versailles Saint-Quentin-en-Yvelines,

France

Yoann Gaboreau, Université Grenoble

Alpes, France

\section{*Correspondence:}

Chris B. Del Mar, Centre for Research in Evidence-Based Practice, Bond

University, 14 University Drive Gold

Coast, QLD 4229, Australia

e-mail:cdelmar@bond.edu.au
Numerous opportunities are available in primary care for alleviating the crisis of increasing antibiotic resistance. Preventing patients from developing an acute respiratory infection (ARI) will obviate any need for antibiotic use downstream. Hygiene measures such as physical barriers and hand hygiene, and possibly vaccination and exercise, may be effective. Also, a large range of complementary and alternative medicines (e.g. zinc, vitamin $\mathrm{C}$ and probiotics) are proposed for preventing and treating ARIs, but evidence for efficacy is scarce.

General practitioners' (GPs) attitudes towards antibiotic prescribing are a major factor in the prescribing for ARIs. Professional interventions with educational components are effective, although they have modest effects, and are expensive. GPs' perceptions - that mistakenly assume as a default that patients want antibiotics for their ARIs - are often wrong. Shared decision making might be a solution, as it enables clinician and patient to participate jointly in making a health decision, having discussed the options together with the evidence for their harms as well as benefits.

Furthermore, GPs' diagnostic uncertainty - often leading to an antibiotic prescription "just in case" - might be addressed by exploiting strategies such as safety-netting, e.g., establishing with the patient a priori clearly defined actions to take if the course of the illness deviates from the expected.

None of these strategies or interventions on their own will greatly improve the use of antibiotics for ARIs. However, used in concert, combinations are likely to enable clinicians and health care systems to implement the strategies that will reduce antimicrobial resistance in the future.

Keywords: antibiotic resistance, primary care, prescriptions, behavior, probiotic, steroids

\section{SETTING THE SCENE}

In the past 70 years, antibiotics have been essential in the fight against infectious diseases and have been a contributing factor in the rise in life expectancy (1). However, we are now gradually facing a post-antibiotic era, a time when antibiotics are no longer effective because bacteria have become more and more resistant. The World Health Organisations' 2014 report on global surveillance of antimicrobial resistance reveals that antibiotic resistance is no longer a prediction for the future; it is happening right now, across the world, and is putting at risk the ability to treat common infections in both the community and hospitals (2). Excessive and inappropriate use of antibiotics is considered to be the most important cause of the increasing problems with resistant bacteria (3). Consequences are not only at a population level but also for individual patients, as it is shown that individuals who are prescribed an antibiotic for a respiratory or urinary infection can develop bacterial resistance to that antibiotic for up to 12 months (4).

The majority of antibiotics are prescribed in primary care (5) and mainly for acute respiratory infections (ARIs) (6). ARI is an overall term for a group of illnesses and the most common infections presenting in primary care are acute otitis media, acute sinusitis, acute tonsillitis, acute pharyngitis, acute bronchitis, pneumonia, the common cold, and influenza. These infections are very common in the community and more than $50 \%$ of the adult population experience ARI symptoms during a 6-month period and one-fifth of them will consult a general practitioner (GP) (7). As much as $90 \%$ of patients diagnosed with acute otitis media, acute sinusitis, or acute tonsillitis are treated with antibiotics in some countries $(8,9)$. In US, the antibiotic prescribing rate for acute bronchitis is about $70 \%$ (10), and in Australia (for GP registrars) about 73\% (11), despite evidence suggesting that the antibiotic prescribing rate for this should be near 0 (12).

The solution seems at first to be straightforward: targeting the use of antibiotics in the community - which is where the greatest tonnage is prescribed and the efficacy of their use is most limited (12-15). Within about a year, over $90 \%$ of commensal antibiotic resistance dissipates (4). Despite the existence of guidelines, 
which recommend appropriate prescribing of antibiotics in the community, antibiotics are still prescribed for ARIs much more than guidelines recommend $(16,17)$. The cause of this cognitive dissonance is almost certainly more than simply a matter of prescriber personal habit (18) and requires an understanding of the various reasons, which can drive clinicians to over-prescribe antibiotics for ARIs. The aim of this paper is to provide an overview of the opportunities and strategies for reducing antibiotic use for ARIs in primary care and outline potential areas for future research.

\section{STRATEGIES}

Understanding the events of decision points surrounding an antibiotic prescription for ARIs in primary care can inform strategies to address the problem at each of these points. This paper considers the path from a healthy person, to a person with symptoms of ARIs, to a person consulting a GP, who may or may not be prescribed an antibiotic (Figure 1). The author team discussed and came to consensus on strategies that were likely to be used at each stage of this pathway. We then used keywords and subject headings for each strategy to search CENTRAL and PubMed (up to October
2014) to identify the highest level of evidence available for each strategy, according to conventional hierarchy of evidence (19).

\section{HEALTHY PEOPLE}

Of course, prevention of ARIs in the first place will reduce the whole downstream use of antibiotics.

\section{VACCINATION}

Haemophilus influenzae type b (Hib) is an important cause of pneumonia and meningitis in children, and the Hib vaccine is safe and effective in reducing Hib disease (20). Pneumococcal polysaccharide vaccines are effective in preventing the rarer outcome of invasive pneumococcal disease, but evidence from meta-analysis does not support the routine use of pneumococcal polysaccharide vaccines to prevent all-cause pneumonia or mortality (21). Vaccination is also often proposed for prevention of influenza. In healthy adults, it has been demonstrated to decrease the risk of symptoms of influenza and time off work, but it does not reduce complications or transmission in healthy adults (22). The etiological organisms for ARIs are numerous and the current vaccination options are unlikely to be able to influence more than a tiny proportion of infections.

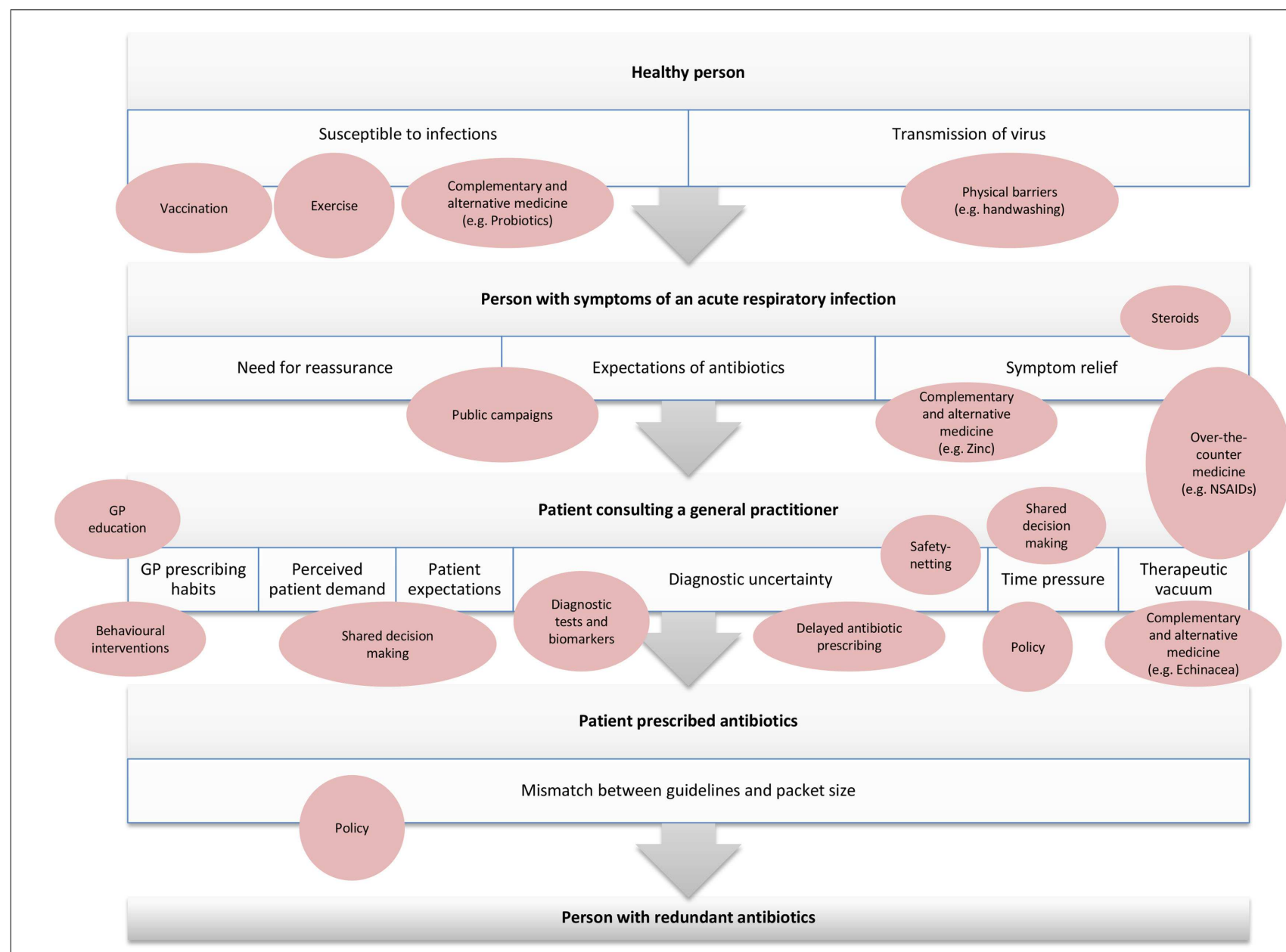

FIGURE 1 | Overview of strategies to minimize antibiotic use in primary care at each stage of the path from healthy person to antibiotic prescription for acute respiratory infection. 


\section{EXERCISE}

Exercise might also reduce the incidence of ARIs, as well as their duration and severity (23).

However, these results need confirmation in other studies before exercise can be recommended for preventing ARIs, a Cochrane review is currently addressing this question (24).

\section{COMPLEMENTARY AND ALTERNATIVE MEDICINE}

Probiotics, Echinacea, and vitamin $\mathrm{C}$ are sometimes suggested for preventing ARIs. Vitamin $\mathrm{C}$ has been used for more than 80 years, although a Cochrane review concludes that it does not reduce the incidence of common cold (25). Another Cochrane review found that trials investigating Echinacea for preventing common cold did not show statistically significant reductions in illness occurrence. However, nearly all prevention trials pointed in the direction of small preventive effects (26). Importantly, the available Echinacea products differ greatly in content of active components and due to significant differences in the preparations tested, it is not possible to draw strong conclusions about the effect of Echinacea in either preventing or treating common colds (26). Probiotics (live microorganisms) are also proposed for preventing ARIs and are found to be marginally better than placebo in terms of the number of participants who experience at least one episode of an acute upper respiratory tract infection [odds ratio (OR) 0.58 ; 95\% confidence interval (CI) 0.36-0.92] (27). Further trials are needed to strengthen the evidence about the potential for probiotics.

\section{HYGIENE AND PHYSICAL BARRIERS}

One way to diminish the number of people with ARIs is through reducing the person-to-person transmission of pathogens by applying physical barriers, hand hygiene, and so on. Respiratory virus spread can be reduced by handwashing, especially around younger children (28). It remains unclear if adding virucidals or antiseptics to normal handwashing with soap is more effective than regular soap (28). There are only limited data on the use of masks and respirators in the community to reduce transmission of virus, but their effectiveness is possibly linked to early, consistent, and correct usage (29).

\section{PEOPLE WITH SYMPTOMS OF AN ACUTE RESPIRATORY INFECTION \\ NEED FOR REASSURANCE AND EXPECTATIONS OF ANTIBIOTICS}

Patients with ARIs are mostly seeking information and reassurance from their GP $(30,31)$. However, many patients overestimate the effectiveness of antibiotics: approximately one-third of patients believe that antibiotics are effective against cold and "flu" (32), and nearly two-thirds believe that acute bronchitis requires antibiotic treatment (33). The important corollary is that those who expect an antibiotic for their ARI are nearly twice as likely to consult their GP when affected by one (7). Pharmacists or other health care providers, coming into contact with patients prior to GP consultation, may be able to change patients' beliefs about the need for antibiotics for ARI by providing advice about self-care and information about the expected duration of the illness (7).

Public campaigns may also have a role to play in addressing public misconceptions about the effectiveness of antibiotics. There have been numerous campaigns in high-income countries to promote appropriate antibiotic use, which vary from simple, low-cost internet campaigns to expensive mass-media campaigns. Although evidence for a cause-effect relation is lacking and the effects are variable, the results of several campaigns suggest that they can decrease the inappropriate use of antibiotics. As an example, in France and Belgium, antibiotic use declined by as much as 27 and $36 \%$, respectively (34).

\section{SYMPTOM RELIEF}

Antibiotics are seldom necessary for treatment of ARIs as most of them are self-limiting conditions often caused by a virus. However, patients with ARIs feel unwell and consequently seek symptom relief $(7,31)$. Several symptomatic drugs as well as complementary and alternative treatments have been proposed. It is known that drugs used for symptomatic treatment of ARIs increases as antibiotic use decreases (35) and it is reasonable to assume that effective symptomatic treatment would reduce pressure on the decision to use antibiotics. Over-the-counter medicine like paracetamol (acetaminophen) and non-steroidal anti-inflammatory drugs (NSAIDs) are commonly used for symptom relief. Paracetamol may help relieve nasal obstruction and rhinorrhea in patients with common cold, but does not appear to improve other cold symptoms like sore throat, malaise, or cough (36). Another Cochrane review found that NSAIDs may improve many analgesia-related symptoms like headache, ear pain, and muscle and joint pain caused by the common cold (37). However, the results of the studies included in the review are diverse and the number of studies for one result is very small.

Steroids are also used for relieving symptoms, especially of acute rhinosinusitis. Intranasal corticosteroids have been found to have a modest effect in the resolution or improvement of symptoms of acute sinusitis [risk ratio (RR) 1.11; 95\% CI 1.04-1.18] in a Cochrane review (38). Another review have demonstrated that oral corticosteroids as a monotherapy appear to be ineffective for treatment of adult patients with clinically diagnosed acute sinusitis (39), but in combination with antibiotics it may be modestly beneficial for short-term relief of symptoms in acute sinusitis [number needed to treat $(\mathrm{NNT})=7$ for resolution or symptom improvement] (39). However, the evidence is limited, as almost all trials included in the review are performed in secondary care and there is a significant risk of bias. A large primary care trial is needed to establish whether oral corticosteroids offer additional benefits over antibiotics in clinically diagnosed acute sinusitis.

A large range of complementary and alternative medicine is available for symptomatic treatment of ARIs. Vitamin C has been proposed for treating respiratory tract infections and weak evidence suggests regular supplementation of vitamin $\mathrm{C}$ might be effective in reducing the duration of common cold by $8 \%$ (4$12 \%)$ in adults and $14 \%(7-21 \%)$ in children (25). Echinacea is also commonly used for the treatment of ARIs, although Echinacea products have not been shown to provide benefits for treating common colds (26). Probiotics have no effect on the mean duration (MD) of an episode of acute upper respiratory tract infection (MD $-0.29 ; 95 \% \mathrm{CI}-3.71$ to 3.13$)$, but their use reduces the antibiotic prescription rate (OR 0.67; 95\% CI 0.45-0.98) (27).

Zinc inhibits replication of virus and has been tested in trials for the treatment of the common cold. A Cochrane review 
demonstrated that when zinc is administered within $24 \mathrm{~h}$ of onset of symptoms, it reduces the duration (days) of common cold symptoms in healthy people (mean difference of -1.03 days; $95 \%$ CI -1.72 to -0.34 ) (40). However, due to heterogeneity of the data results from the review should be interpreted with caution. Heated, humidified air has long been used by people with a common cold, on a theoretical basis that steam may help congested mucus drain better and heat may destroy the cold virus. A Cochrane review of six trials found that steam inhalation provided no consistent benefit in the treatment of the common cold. Three trials found benefits of steam for symptom relief with the common cold (OR $0.31 ; 95 \%$ CI 0.16-0.60). The sample size, however, was small and studies showed significant heterogeneity (41).

Caffeine as an analgesic adjuvant has been discussed for many years. In a Cochrane review based on 19 studies with a total of 7238 patients with different pain conditions, caffeine enhanced the efficacy of paracetamol, ibuprofen, or aspirin with a NNT of about 15 (42). However, only one trial related to ARIs were included in this review $(43,44)$.

Although the body of existing evidence is limited, it suggests that there is minimal benefit for the use of these non-antibiotic alternatives and larger, high quality, primary care-based studies are needed to further explore these alternatives and to develop and test new non-antibiotic treatments for ARIs.

\section{PATIENT CONSULTING A GENERAL PRACTITIONER GP PRESCRIBING HABITS}

There are wide variations in GPs' antibiotic prescribing rates (45, 46) and GPs' attitudes are a major influencing factor (18). GP education is a common component of most trials designed to address this issue $(47,48)$. One approach focuses on better communication skills: GPs who receive specific communication skills training prescribe fewer antibiotics for patients with ARIs [27\% compared with $54 \%$ in the no training group $(P<0.01)](49)$, even at long-term follow-up (50). A significant long-term effect has also been demonstrated on the prescribing behavior of GPs after participating in a medical educational program (betweengroup difference after 30-month 1.99\%, 95\% CI 0.56-3.42) (35). However, the effect of these comprehensive interventions seems quite modest when estimating the precise number of antibiotic prescriptions saved. The number of antibiotic prescriptions for lower respiratory tract infections was reduced from 2 prescriptions/week/GP to 1 prescription/week/GP in the study by Cals et al. (49) and a reduction in total antibiotic prescriptions from 11 prescriptions/week/GP to 8.5 prescriptions/week/GP was demonstrated in the French study (35). Although it seems very difficult to change GPs' behavior, a simple intervention was recently carried out in US. This was a behavioral "nudge" in the format of a public commitment device - a poster-sized letter signed by clinicians and posted in the examination room. The intervention resulted in a $20 \%$ absolute reduction in inappropriate antibiotic prescribing for ARIs (51).

\section{PERCEIVED PATIENT DEMAND AND PATIENT EXPECTATIONS}

General practitioners often feel patients with ARIs are consulting with an expectation of antibiotics $(52,53)$. Back in 1998, Butler et al. found that: "Doctors knew of the evidence for marginal effectiveness, yet often prescribed for good relationships with patients" (54). This paradox is still current and may be one of the main contributors to the ongoing over-prescribing of antibiotics for ARIs. However, GPs often mistakenly assume their patients' expectations (55). Patient satisfaction is associated with reassurance and information and not just with an antibiotic prescription $(30,31)$. Shared decision making may have an important role to play in addressing patient expectations and concerns. In the shared decision making process, evidence is brought into the discussion with patients, and their concerns and expectations are explicitly sought (56). The process enables clinician and patient to participate jointly in making a health decision, having discussed the options and their benefits and harms, and having considered the patient's values, preferences, and circumstances (57). As the benefit-harm balance of antibiotics is very finely balanced, communicating this to patients may reduce their desire for antibiotics. Shared decision making has been shown to reduce antibiotic prescribing for ARIs in a number of trials (58-60), and a Cochrane review of this is currently underway (61).

\section{DIAGNOSTIC UNCERTAINTY}

The relationship between diagnostic uncertainty and antibiotic misuse has been demonstrated in several studies (18). Clinicians typically only have a few minutes to decide if the patient has a serious infection, or is at risk of complications. The point-of-care test, C-reactive protein (CRP), has been proposed as a solution to this clinical dilemma. It is widely used in some European primary care settings $(62,63)$, while in other countries it is barely used (64). CRP-testing has been shown to significantly reduce antibiotic prescribing for patients with ARIs (RR 0.75, 95\% CI = 0.67-0.83) (65) and it might be a useful strategy to increase patient satisfaction without compromising patient recovery (49).

In nearly 30 years, the rapid antigen detection test has been used for detection of Lancefield group A $\beta$-hemolytic streptococci (GABHS) in patients with a sore throat. Not all patients with a positive test and throat symptoms have an infection caused by GABHS $(66,67)$, and they may not benefit from antibiotic treatment. Still its use has been shown to significantly reduce antibiotic prescription for sore throat by more than $20 \%(68,69)$. However, compared with the use of a clinical score alone to guide antibiotic prescribing, there is no effect of additional use of rapid antigen detection test in patients with a sore throat either for symptom management or for antibiotic use (69).

Procalcitonin is a promising biomarker for identification of bacterial infections. So far, meta-analyses have mainly investigated the use of procalcitonin as a diagnostic marker for sepsis $(70,71)$, but a Cochrane review from 2012 concluded that procalcitonin is a safe and effective tool to guide clinical decisions for antibiotic initiation and duration of treatment in patients with ARIs (72). However, evidence for the use of procalcitonin in primary care for ARIs is still limited and further trials are needed to assess the diagnostic accuracy of this biomarker in primary care.

General practitioners may prescribe antibiotics to prevent complications like quinsy, mastoiditis, and pneumonia, although the rates of serious complications are low in modern developed countries $(73,74)$. History, examination, and scores to predict bacterial infection cannot usefully identify those who will develop 
complications (75). GPs will need to rely on strategies such as "safety-netting" in managing the diagnostic uncertainty. The concept of "safety-netting" - that is, establishing clearly defined actions to take if the course of the illness deviates from the expected was introduced in a book about primary care consulting in 1990s (76). Evaluation of this strategy and its effects on patient care is needed (77). Delayed prescribing is actually one form of safetynetting and is an effective strategy to deal with the diagnostic uncertainty. A Cochrane review demonstrated that delayed prescribing resulted in $32 \%$ of patients using antibiotics compared to $93 \%$ of patients in the immediate prescription group (78). Some of the included studies in the review found that in patients with acute otitis media and sore throat prescribing immediate antibiotics was more effective than delayed prescribing for fever, pain, and malaise (78). However, a newly published randomized controlled trial showed little difference in symptom control between strategies involving no prescription, immediate prescription, or delayed prescription (79).

\section{TIME PRESSURE}

Busy GPs are more liberal with antibiotics for ARIs than less busy GPs, and use a greater proportion of broad-spectrum antibiotics (80). Unfortunately, GPs often have limited time for consultations dealing with patients with acute illness such as ARIs. In many countries, GPs are, among other things, increasingly required to take care of patients with chronic diseases. However, consultations for acute illness should also be prioritized as the pressure of limited time in primary care is correlated with antibiotic prescribing (18). Moreover, the cycle is perpetuating as patients who have been previously prescribed antibiotics for ARIs are more likely to re-consult their GP rather than self-manage for subsequent infections (81). This suggests that investing just a few minutes in shared decision making might be effective at reducing antibiotic prescribing (58) - as well as reducing future visits.

\section{THERAPEUTIC VACUUM}

How can GPs manage the therapeutic vacuums left by not prescribing antibiotics? Over-the-counter drugs, complementary and alternative medicines, or steroids might be recommended for patients with some ARIs. Others might benefit from advice on preventing future ARIs by routine handwashing. Most patients are satisfied with a good explanation of their symptoms (30), and information of the minimal benefits of antibiotics for ARIs to understand the benefit-harm trade-off.

\section{MISMATCH BETWEEN GUIDELINES AND PACKET SIZE}

Often patients end up with leftover antibiotics because there is a mismatch between guidelines and the packet size of antibiotics. This is a problem because leftovers are saved and used for selfmedication (82). Antibiotics that have been prescribed for one disease are subsequently used as self-medication for repeated episodes of the same disease, and also for other symptoms that are not necessarily caused by a bacterial illness (83). Redundant antibiotics are a potentially remediable source of antibiotic overuse and national regulatory authorities should ensure that the recommended dose of an antibiotic match the packet prescribed.

\section{CONCLUSION}

There are numerous opportunities available in primary care for alleviating the crisis of increasing antibiotic resistance. None of these strategies or interventions on their own will greatly improve the use of antibiotics for ARIs. However, used in concert, combinations are likely to enable clinicians and health care systems to implement the strategies that will reduce antimicrobial resistance in the future.

\section{ACKNOWLEDGMENT}

We received research funding from the Australian NHMRC.

\section{REFERENCES}

1. Fleming A. On the antibacterial action of cultures of a penicillium, with special reference to their use in the isolation of B. influenzae. 1929. Bull World Health Organ (2001) 79:780-90.

2. World Health Organization. Antimicrobial Resistance: Global Report on Surveillance (2014). Available from: http://www.who.int/drugresistance/documents/ surveillancereport/en/

3. Goossens H, Ferech M, Vander Stichele R, Elseviers M. Outpatient antibiotic use in Europe and association with resistance: a cross-national database study. Lancet (2005) 365:579-87. doi:10.1016/S0140-6736(05)70799-6

4. Costelloe C, Metcalfe C, Lovering A, Mant D, Hay AD. Effect of antibiotic prescribing in primary care on antimicrobial resistance in individual patients: systematic review and meta-analysis. BMJ (2010) 340:c2096. doi:10.1136/bmj. c2096

5. DANMAP. Use of Antimicrobial Agents and Occurrence of Antimicrobial Resistance in Bacteria from Food Animals, Food and Humans in Denmark (2013). Available from: http://www.danmap.org

6. van den Broek d'Obrenan J, Verheij TJ, Numans ME, van der Velden AW. Antibiotic use in Dutch primary care: relation between diagnosis, consultation and treatment. J Antimicrob Chemother (2014) 69:1701-7. doi:10.1093/jac/dku005

7. McNulty CA, Nichols T, French DP, Joshi P, Butler CC. Expectations for consultations and antibiotics for respiratory tract infection in primary care: the RTI clinical iceberg. Br J Gen Pract (2013) 63:e429-36. doi:10.3399/bjgp13X669149

8. Kung K, Wong CK, Wong SY, Lam A, Chan CK, Griffiths S, et al. Patient presentation and physician management of upper respiratory tract infections: a retrospective review of over 5 million primary clinic consultations in Hong Kong. BMC Fam Pract (2014) 15:95. doi:10.1186/1471-2296-15-95

9. Hansen MP, Jarbol DE, Gahrn-Hansen B, Depont Christensen R, Munck A, Ellegaard Trankjaer Ryborg C, et al. Treatment of acute otitis media in general practice: quality variations across countries. Fam Pract (2012) 29:63-8. doi:10.1093/fampra/cmr042

10. Barnett ML, Linder JA. Antibiotic prescribing for adults with acute bronchitis in the United States, 1996-2010. JAMA (2014) 311:2020-2. doi:10.1001/jama. 2013.286141

11. Dallas A, Magin P, Morgan S, Tapley A, Henderson K, Ball J, et al. Antibiotic prescribing for respiratory infections: a cross-sectional analysis of the ReCEnT study exploring the habits of early-career doctors in primary care. Fam Pract (2015) 32(1):49-55. doi:10.1093/fampra/cmu069

12. Smith SM, Fahey T, Smucny J, Becker LA. Antibiotics for acute bronchitis. Cochrane Database Syst Rev (2014) 3:CD000245. doi:10.1002/14651858. CD000245.pub3

13. Venekamp RP, Sanders S, Glasziou PP, Del Mar CB, Rovers MM. Antibiotics for acute otitis media in children. Cochrane Database Syst Rev (2013) 1:CD000219. doi:10.1002/14651858.CD000219.pub3

14. Ahovuo-Saloranta A, Rautakorpi UM, Borisenko OV, Liira H, Williams JW Jr, Mäkelä M. Antibiotics for acute maxillary sinusitis in adults. Cochrane Database Syst Rev (2014) 2:CD000243. doi:10.1002/14651858.CD000243.pub3

15. Spinks A, Glasziou PP, Del Mar CB. Antibiotics for sore throat. Cochrane Database Syst Rev (2013) 11:CD000023. doi:10.1002/14651858.CD000023.pub4

16. Jorgensen LC, Friis Christensen S, Cordoba Currea G, Llor C, Bjerrum L. Antibiotic prescribing in patients with acute rhinosinusitis is not in agreement with European recommendations. Scand J Prim Health Care (2013) 31:101-5. doi: $10.3109 / 02813432.2013 .788270$

17. Urkin J, Allenbogen M, Friger M, Vinker S, Reuveni H, Elahayani A. Acute pharyngitis: low adherence to guidelines highlights need for greater flexibility 
in managing paediatric cases. Acta Paediatr (2013) 102:1075-80. doi:10.1111/ apa.12364

18. Teixeira Rodrigues A, Roque F, Falcao A, Figueiras A, Herdeiro MT. Understanding physician antibiotic prescribing behaviour: a systematic review of qualitative studies. Int J Antimicrob Agents (2013) 41:203-12. doi:10.1016/j.ijantimicag. 2012.09.003

19. Hoffmann T, Bennett S, Del Mar C. Evidence-Based Practice Across the Health Professions. 2nd ed. Sydney: Elsevier (2013).

20. Swingler GH, Michaels D, Hussey GGD. Conjugate vaccines for preventing Haemophilus influenzae type B infections. Cochrane Database Syst Rev (2007) 2:CD001729. doi:10.1002/14651858.CD001729.pub2

21. Moberley S, Holden J, Tatham DP, Andrews RM. Vaccines for preventing pneumococcal infection in adults. Cochrane Database Syst Rev (2013) 1:CD000422. doi:10.1002/14651858.CD000422.pub3

22. Demicheli V, Jefferson T, Al-Ansary LA, Ferroni E, Rivetti A, Di Pietrantonj C. Vaccines for preventing influenza in healthy adults. Cochrane Database Syst Rev (2014) 3:CD001269. doi:10.1002/14651858.CD001269.pub5

23. Barrett B, Hayney MS, Muller D, Rakel D, Ward A, Obasi CN, et al. Meditation or exercise for preventing acute respiratory infection: a randomized controlled trial. Ann Fam Med (2012) 10:337-46. doi:10.1370/afm.1376

24. Grande AJ, Keogh J, Hoffmann T, Del Mar CB, Peccin MS. Exercise for acute respiratory infections (Protocol). Cochrane Database Syst Rev (2013) 6:CD010596. doi:10.1002/14651858.CD010596

25. Hemilä H, Chalker E. Vitamin C for preventing and treating the common cold. Cochrane Database Syst Rev (2013) 1:CD000980. doi:10.1002/14651858. CD000980.pub4

26. Karsch-Völk M, Barrett B, Kiefer D, Bauer R, Ardjomand-Woelkart K, Linde K. Echinacea for preventing and treating the common cold. Cochrane Database Syst Rev (2014) 2:CD000530. doi:10.1002/14651858.CD000530.pub3

27. Hao Q, Lu Z, Dong BR, Huang CQ, Wu T. Probiotics for preventing acute upper respiratory tract infections. Cochrane Database Syst Rev (2011) 9:CD006895. doi:10.1002/14651858.CD006895.pub2

28. Jefferson T, Del Mar CB, Dooley L, Ferroni E, Al-Ansary LA, Bawazeer GA et al. Physical interventions to interrupt or reduce the spread of respiratory viruses. Cochrane Database Syst Rev (2011) 7:CD006207. doi:10.1002/14651858. CD006207.pub4

29. Bin-Reza F, Lopez Chavarrias V, Nicoll A, Chamberland ME. The use of masks and respirators to prevent transmission of influenza: a systematic review of the scientific evidence. Influenza Other Respi Viruses (2012) 6:257-67. doi:10.1111/j.1750-2659.2011.00307.x

30. Welschen I, Kuyvenhoven M, Hoes A, Verheij T. Antibiotics for acute respiratory tract symptoms: patients' expectations, GPs' management and patient satisfaction. Fam Pract (2004) 21:234-7. doi:10.1093/fampra/cmh303

31. van Driel ML, De Sutter A, Deveugele M, Peersman W, Butler CC, De Meyere M, et al. Are sore throat patients who hope for antibiotics actually asking for pain relief? Ann Fam Med (2006) 4:494-9. doi:10.1370/afm.609

32. Hoffmann K, Ristl R, Heschl L, Stelzer D, Maier M. Antibiotics and their effects: what do patients know and what is their source of information? Eur J Public Health (2014) 24:502-7. doi:10.1093/eurpub/ckt112

33. Cals JW, Boumans D, Lardinois RJ, Gonzales R, Hopstaken RM, Butler CC, et al. Public beliefs on antibiotics and respiratory tract infections: an internetbased questionnaire study. Br J Gen Pract (2007) 57:942-7. doi:10.3399/ 096016407782605027

34. Huttner B, Goossens H, Verheij T, Harbarth S. Characteristics and outcomes of public campaigns aimed at improving the use of antibiotics in outpatients in high-income countries. Lancet Infect Dis (2010) 10:17-31. doi:10.1016/S14733099(09)70305-6

35. Le Corvoisier P, Renard V, Roudot-Thoraval F, Cazalens T, Veerabudun K, Canoui-Poitrine F, et al. Long-term effects of an educational seminar on antibiotic prescribing by GPs: a randomised controlled trial. Br J Gen Pract (2013) 63:e455-64. doi:10.3399/bjgp13X669176

36. Li S, Yue J, Dong BR, Yang M, Lin X, Wu T. Acetaminophen (paracetamol) for the common cold in adults. Cochrane Database Syst Rev (2013) 7:CD008800. doi:10.1002/14651858.CD008800.pub2

37. Kim SY, Chang YJ, Cho HM, Hwang YW, Moon YS. Non-steroidal antiinflammatory drugs for the common cold. Cochrane Database Syst Rev (2013) 6:CD006362. doi:10.1002/14651858.CD006362.pub3
38. Zalmanovici Trestioreanu A, Yaphe J. Intranasal steroids for acute sinusitis. Cochrane Database Syst Rev (2013) 12:CD005149. doi:10.1002/14651858. CD005149.pub4

39. Venekamp RP, Thompson MJ, Hayward G, Heneghan CJ, Del Mar CB, Perera $\mathrm{R}$, et al. Systemic corticosteroids for acute sinusitis. Cochrane Database Syst Rev (2014) 3:CD008115. doi:10.1002/14651858.CD008115.pub3

40. Singh M, Das RR. Zinc for the common cold. Cochrane Database Syst Rev (2013) 6:CD001364. doi:10.1002/14651858.CD001364.pub4

41. Singh M, Singh M. Heated, humidified air for the common cold. Cochrane Database Syst Rev (2013) 6:CD001728. doi:10.1002/14651858.CD001728.pub5

42. Derry CJ, Derry S, Moore RA. Caffeine as an analgesic adjuvant for acute pain in adults. Cochrane Database Syst Rev (2012) 3:CD009281. doi:10.1002/14651858. CD009281.pub2

43. Schachtel BP, Fillingim JM, Lane AC, Thoden WR, Baybutt RI. Caffeine as an analgesic adjuvant. A double-blind study comparing aspirin with caffeine to aspirin and placebo in patients with sore throat. Arch Intern Med (1991) 151:733-7. doi:10.1001/archinte.1991.00400040081017

44. Thomas M, Del Mar C, Glasziou P. How effective are treatments other than antibiotics for acute sore throat? Br J Gen Pract (2000) 50:817-20.

45. Gulliford MC, Dregan A, Moore MV, Ashworth M, Staa T, McCann G, et al. Continued high rates of antibiotic prescribing to adults with respiratory tract infection: survey of 568 UK general practices. BMJ Open (2014) 4:e006245. doi:10.1136/bmjopen-2014-006245

46. Hawker JI, Smith S, Smith GE, Morbey R, Johnson AP, Fleming DM, et al Trends in antibiotic prescribing in primary care for clinical syndromes subject to national recommendations to reduce antibiotic resistance, UK 1995-2011: analysis of a large database of primary care consultations. J Antimicrob Chemother (2014) 69:3423-30. doi:10.1093/jac/dku291

47. Arnold SR, Straus SE. Interventions to improve antibiotic prescribing practices in ambulatory care. Cochrane Database Syst Rev (2005) 4:CD003539. doi:10.1002/14651858.CD003539.pub2

48. van der Velden AW, Pijpers EJ, Kuyvenhoven MM, Tonkin-Crine SK, Little P, Verheij TJ. Effectiveness of physician-targeted interventions to improve antibiotic use for respiratory tract infections. Br J Gen Pract (2012) 62:e801-7. doi:10.3399/bjgp12X659268

49. Cals JW, Butler CC, Hopstaken RM, Hood K, Dinant GJ. Effect of point of care testing for $\mathrm{C}$ reactive protein and training in communication skills on antibiotic use in lower respiratory tract infections: cluster randomised trial. BMJ (2009) 338:b1374. doi:10.1136/bmj.b1374

50. Cals JW, de Bock L, Beckers PJ, Francis NA, Hopstaken RM, Hood K, et al. Enhanced communication skills and C-reactive protein point-of-care testing for respiratory tract infection: 3.5-year follow-up of a cluster randomized trial. Ann Fam Med (2013) 11:157-64. doi:10.1370/afm.1477

51. Meeker D, Knight TK, Friedberg MW, Linder JA, Goldstein NJ, Fox CR, et al. Nudging guideline-concordant antibiotic prescribing: a randomized clinical trial. JAMA Intern Med (2014) 174:425-31. doi:10.1001/jamainternmed. 2013.14191

52. Britten N, Ukoumunne O. The influence of patients' hopes of receiving a prescription on doctors' perceptions and the decision to prescribe: a questionnaire survey. BMJ (1997) 315:1506-10. doi:10.1136/bmj.315.7121.1506

53. Coenen S, Michiels B, Renard D, Denekens J, Van Royen P. Antibiotic prescribing for acute cough: the effect of perceived patient demand. Br J Gen Pract (2006) 56:183-90.

54. Butler CC, Rollnick S, Pill R, Maggs-Rapport F, Stott N. Understanding the culture of prescribing: qualitative study of general practitioners' and patients' perceptions of antibiotics for sore throats. BMJ (1998) 317:637-42. doi:10.1136/ bmj.317.7159.637

55. Cockburn J, Pit S. Prescribing behaviour in clinical practice: patients' expectations and doctors' perceptions of patients' expectations - a questionnaire study. BMJ (1997) 315:520-3. doi:10.1136/bmj.315.7107.520

56. Stacey D, Légaré F, Col NF, Bennett CL, Barry MJ, Eden KB, et al. Decision aids for people facing health treatment or screening decisions. Cochrane Database Syst Rev (2014) 1:CD001431. doi:10.1002/14651858.CD001431.pub4

57. Hoffmann TC, Legare F, Simmons MB, McNamara K, McCaffery K, Trevena LJ, et al. Shared decision making: what do clinicians need to know and why should they bother? Med J Aust (2014) 201:35-9. doi:10.5694/mjal4. 00002 
58. Legare F, Labrecque M, Cauchon M, Castel J, Turcotte S, Grimshaw J. Training family physicians in shared decision-making to reduce the overuse of antibiotics in acute respiratory infections: a cluster randomized trial. CMAJ (2012) 184:E726-34. doi:10.1503/cmaj.120568

59. Butler CC, Simpson SA, Dunstan F, Rollnick S, Cohen D, Gillespie D, et al. Effectiveness of multifaceted educational programme to reduce antibiotic dispensing in primary care: practice based randomised controlled trial. BMJ (2012) 344:d8173. doi:10.1136/bmj.d8173

60. Little P, Stuart B, Francis N, Douglas E, Tonkin-Crine S, Anthierens S, et al. Effects of internet-based training on antibiotic prescribing rates for acute respiratory-tract infections: a multinational, cluster, randomised, factorial, controlled trial. Lancet (2013) 382:1175-82. doi:10.1016/S0140-6736(13) 60994-0

61. Coxeter P, Hoffmann T, Del Mar CB. Shared decision making for acute respiratory infections in primary care (Protocol). Cochrane Database Syst Rev (2014) 1:CD010907. doi:10.1002/14651858.CD010907

62. Andre M, Schwan A, Odenholt I. The use of CRP tests in patients with respiratory tract infections in primary care in Sweden can be questioned. Scand I Infect Dis (2004) 36:192-7. doi:10.1080/00365540410019372

63. Christensen SF, Jorgensen LC, Cordoba G, Llor C, Siersma V, Bjerrum L. Marked differences in GPs' diagnosis of pneumonia between Denmark and Spain: a cross-sectional study. Prim Care Respir J (2013) 22:454-8. doi:10.4104/pcrj. 2013.00093

64. Howick J, Cals JW, Jones C, Price CP, Pluddemann A, Heneghan C, et al. Current and future use of point-of-care tests in primary care: an international survey in Australia, Belgium, The Netherlands, the UK and the USA. BMJ Open (2014) 4:e005611. doi:10.1136/bmjopen-2014-005611

65. Huang Y, Chen R, Wu T, Wei X, Guo A. Association between point-of-care CRP testing and antibiotic prescribing in respiratory tract infections: a systematic review and meta-analysis of primary care studies. Br J Gen Pract (2013) 63:e787-94. doi:10.3399/bjgp13X674477

66. Gunnarsson RK, Holm SE, Soderstrom M. The prevalence of beta-haemolytic streptococci in throat specimens from healthy children and adults. Implications for the clinical value of throat cultures. Scand J Prim Health Care (1997) 15:149-55. doi:10.3109/02813439709018506

67. Shaikh N, Leonard E, Martin JM. Prevalence of streptococcal pharyngitis and streptococcal carriage in children: a meta-analysis. Pediatrics (2010) 126:e557-64. doi:10.1542/peds.2009-2648

68. Llor C, Madurell J, Balague-Corbella M, Gomez M, Cots JM. Impact on antibiotic prescription of rapid antigen detection testing in acute pharyngitis in adults: a randomised clinical trial. Br J Gen Pract (2011) 61:e244-51. doi:10.3399/bjgp11X572436

69. Little P, Hobbs FD, Moore M, Mant D, Williamson I, McNulty C, et al. Clinical score and rapid antigen detection test to guide antibiotic use for sore throats: randomised controlled trial of PRISM (primary care streptococcal management). BMJ (2013) 347:f5806. doi:10.1136/bmj.f5806

70. Wacker C, Prkno A, Brunkhorst FM, Schlattmann P. Procalcitonin as a diagnostic marker for sepsis: a systematic review and meta-analysis. Lancet Infect Dis (2013) 13:426-35. doi:10.1016/S1473-3099(12)70323-7

71. Tang BM, Eslick GD, Craig JC, McLean AS. Accuracy of procalcitonin for sepsis diagnosis in critically ill patients: systematic review and meta-analysis. Lancet Infect Dis (2007) 7:210-7. doi:10.1016/S1473-3099(07)70052-X

72. Schuetz P, Muller B, Christ-Crain M, Stolz D, Tamm M, Bouadma L, et al. Procalcitonin to initiate or discontinue antibiotics in acute respiratory tract infections. Cochrane Database Syst Rev (2012) 9:CD007498. doi:10.1002/14651858. CD007498.pub2
73. Petersen I, Johnson AM, Islam A, Duckworth G, Livermore DM, Hayward AC. Protective effect of antibiotics against serious complications of common respiratory tract infections: retrospective cohort study with the UK general practice research database. BMJ (2007) 335:982. doi:10.1136/bmj.39345. 405243.BE

74. Thompson PL, Gilbert RE, Long PF, Saxena S, Sharland M, Wong IC. Effect of antibiotics for otitis media on mastoiditis in children: a retrospective cohort study using the United Kingdom general practice research database. Pediatrics (2009) 123:424-30. doi:10.1542/peds.2007-3349

75. Little P, Stuart B, Hobbs FD, Butler CC, Hay AD, Campbell J, et al. Predictors of suppurative complications for acute sore throat in primary care: prospective clinical cohort study. BMJ (2013) 347:f6867. doi:10.1136/bmj.f6867

76. Neighbour R. The Inner Consultation. 2nd ed. Oxford: Radcliffe Publishing (2004).

77. Almond S, Mant D, Thompson M. Diagnostic safety-netting. Br J Gen Pract (2009) 59:872-4. doi:10.3399/bjgp09X472971

78. Spurling GK, Del Mar CB, Dooley L, Foxlee R, Farley R. Delayed antibiotics for respiratory infections. Cochrane Database Syst Rev (2013) 4:CD004417. doi:10.1002/14651858.CD004417.pub4

79. Little P, Moore M, Kelly J, Williamson I, Leydon G, McDermott L, et al. Delayed antibiotic prescribing strategies for respiratory tract infections in primary care: pragmatic, factorial, randomised controlled trial. BMJ (2014) 348:g1606. doi:10.1136/bmj.g1606

80. Gjelstad S, Straand J, Dalen I, Fetveit A, Strom H, Lindbaek M. Do general practitioners' consultation rates influence their prescribing patterns of antibiotics for acute respiratory tract infections? J Antimicrob Chemother (2011) 66:2425-33. doi:10.1093/jac/dkr295

81. Moore M, Little P, Rumsby K, Kelly J, Watson L, Warner G, et al. Effect of antibiotic prescribing strategies and an information leaflet on longer-term reconsultation for acute lower respiratory tract infection. Br J Gen Pract (2009) 59:728-34. doi:10.3399/bjgp09X472601

82. Muras M, Krajewski J, Nocun M, Godycki-Cwirko M. A survey of patient behaviours and beliefs regarding antibiotic self-medication for respiratory tract infections in Poland. Arch Med Sci (2013) 9:854-7. doi:10.5114/aoms.2012.29217

83. Grigoryan L, Burgerhof JG, Haaijer-Ruskamp FM, Degener JE, Deschepper R, Monnet DL, et al. Is self-medication with antibiotics in Europe driven by prescribed use? J Antimicrob Chemother (2007) 59:152-6. doi:10.1093/jac/dkl457

Conflict of Interest Statement: The authors declare that the research was conducted in the absence of any commercial or financial relationships that could be construed as a potential conflict of interest.

Received: 12 December 2014; accepted: 10 February 2015; published online: 24 February 2015.

Citation: Hansen MP, Hoffmann TC, McCullough AR, van Driel ML and Del Mar CB (2015) Antibiotic resistance: what are the opportunities for primary care in alleviating the crisis? Front. Public Health 3:35. doi: 10.3389/fpubh.2015.00035

This article was submitted to Family Medicine and Primary Care, a section of the journal Frontiers in Public Health.

Copyright ( $) 2015$ Hansen, Hoffmann, McCullough, van Driel and Del Mar. This is an open-access article distributed under the terms of the Creative Commons Attribution License (CC BY). The use, distribution or reproduction in other forums is permitted, provided the original author(s) or licensor are credited and that the original publication in this journal is cited, in accordance with accepted academic practice. No use, distribution or reproduction is permitted which does not comply with these terms. 